\title{
Notes on the vocalizations of Rufous-brown Solitaire (Cichlopsis
} leucogenys)

\section{Peter Boesman}

In the following we briefly analyze and compare voice of the different races of Rufous-brown Solitaire (Cichlopsis leucogenys). We also try to quantify the extent of any vocal differences using the criteria proposed by Tobias et al. (2010), as a support for taxonomic review. We have made use of sound recordings available on-line from Xeno Canto (XC) and Macaulay Library (ML).

An overview of vocalizations per race, illustrated with sonograms:

\section{chubbi}
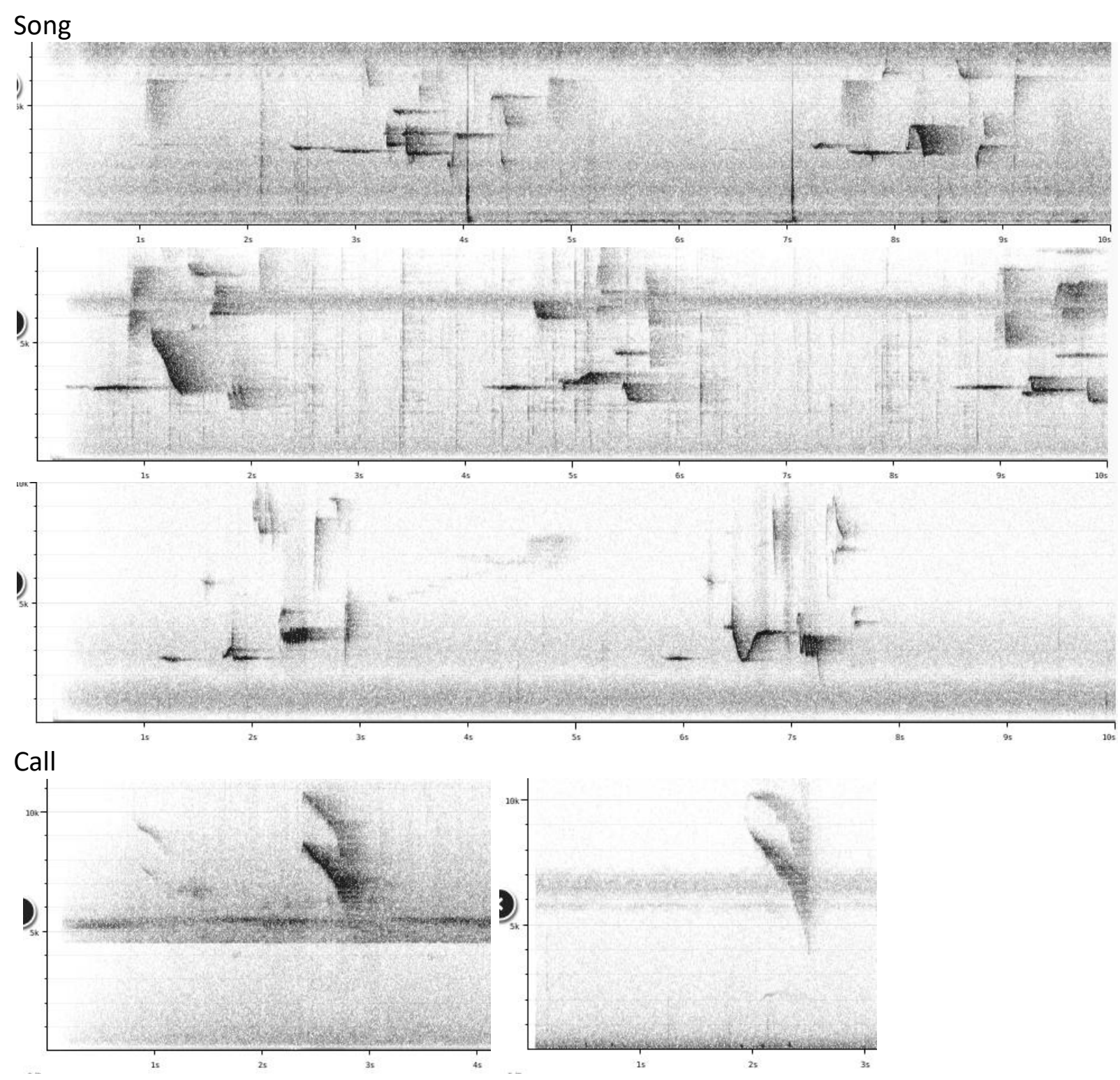


\section{HANDBOOK OF THE \\ BIRDSPITTE WORLD Alve}

\section{ORNITHOLOGICAL NOTES}

peruviana

Voice unknown.

\section{gularis}

Song (Identification of songs uncertain!)

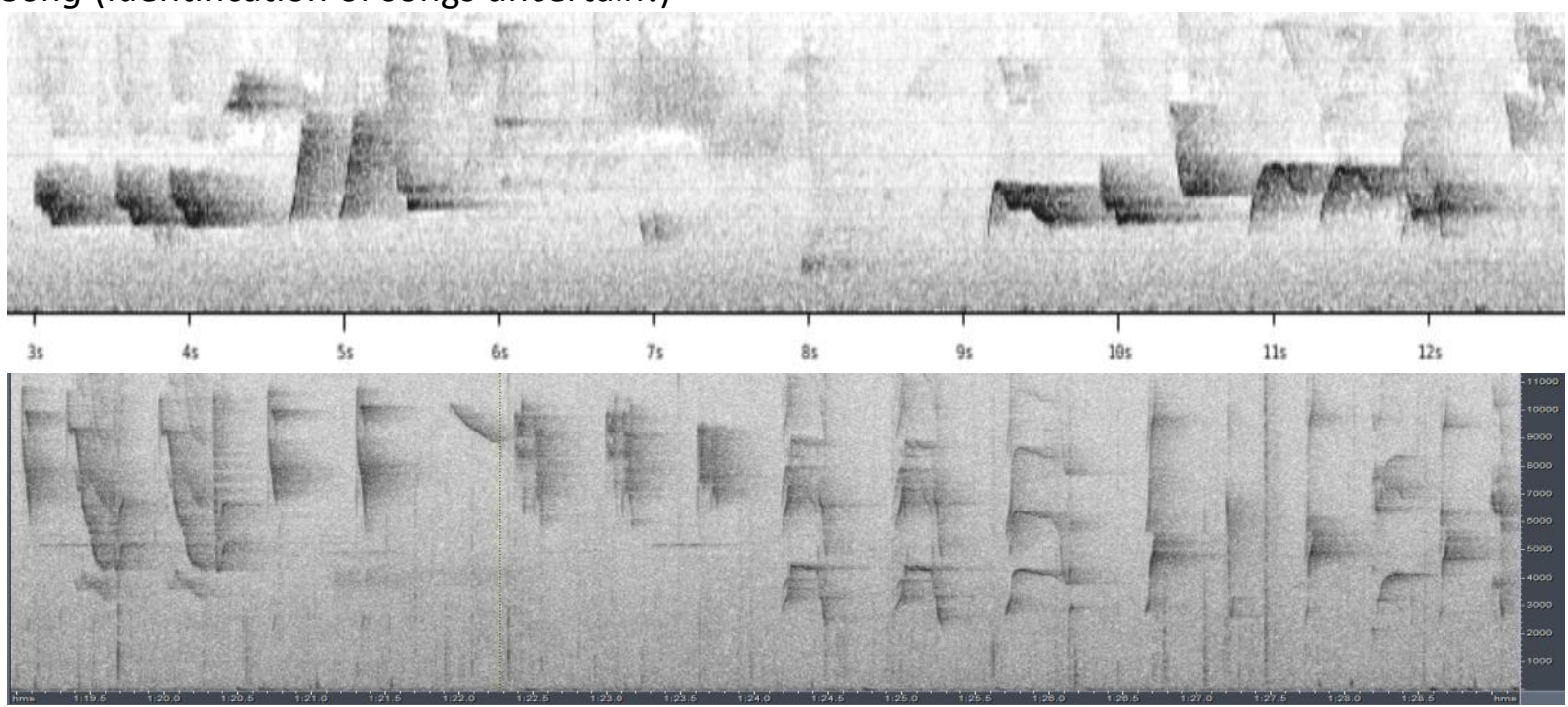

Call

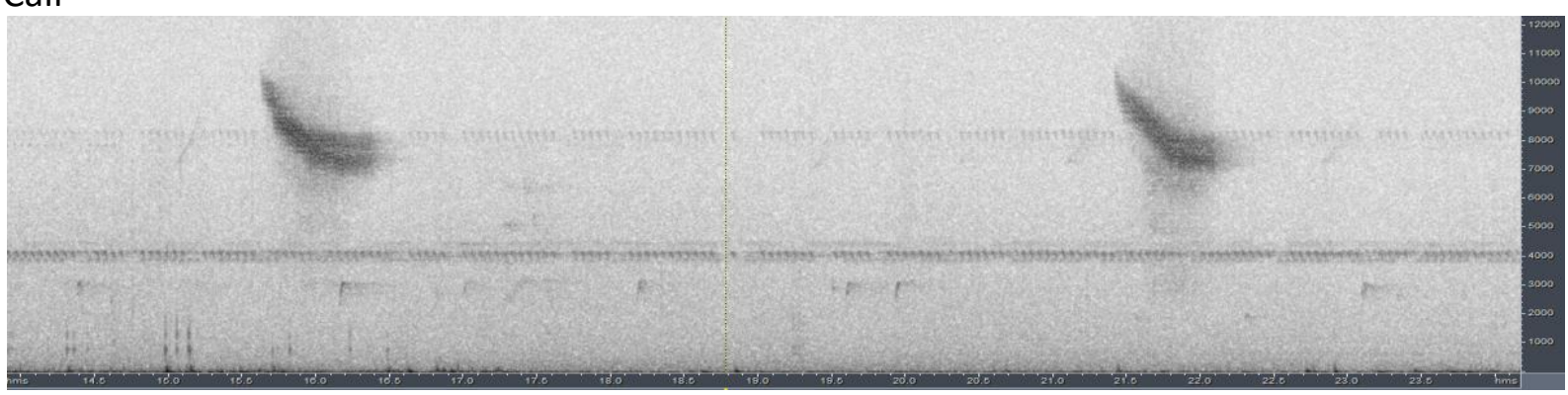

\section{leucogenys}

Song
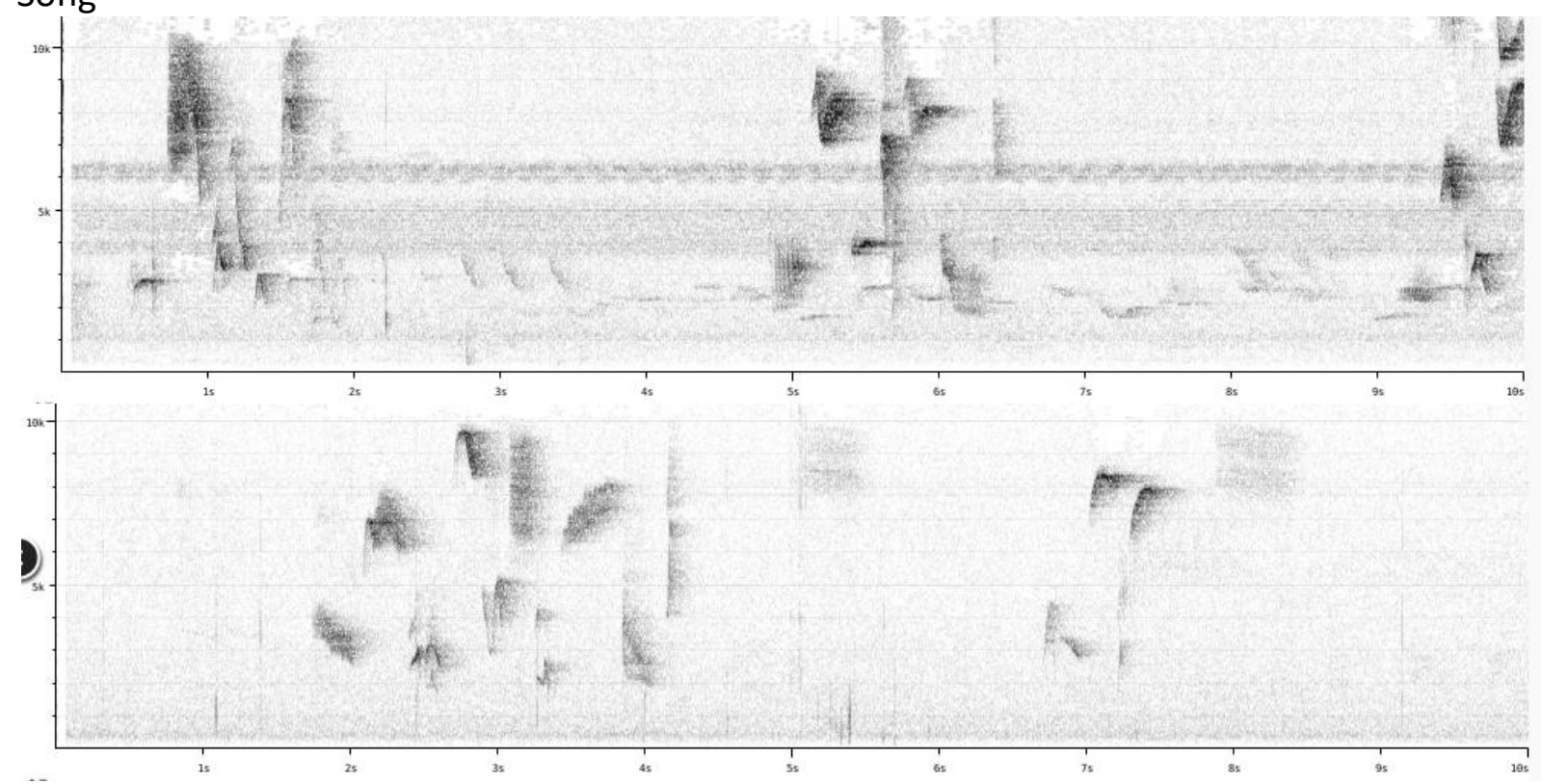


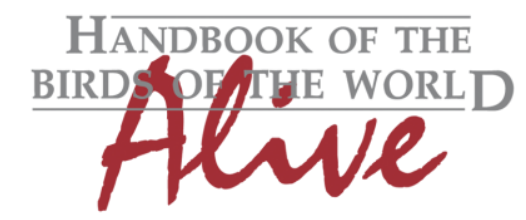

\section{ORNITHOLOGICAL NOTES}

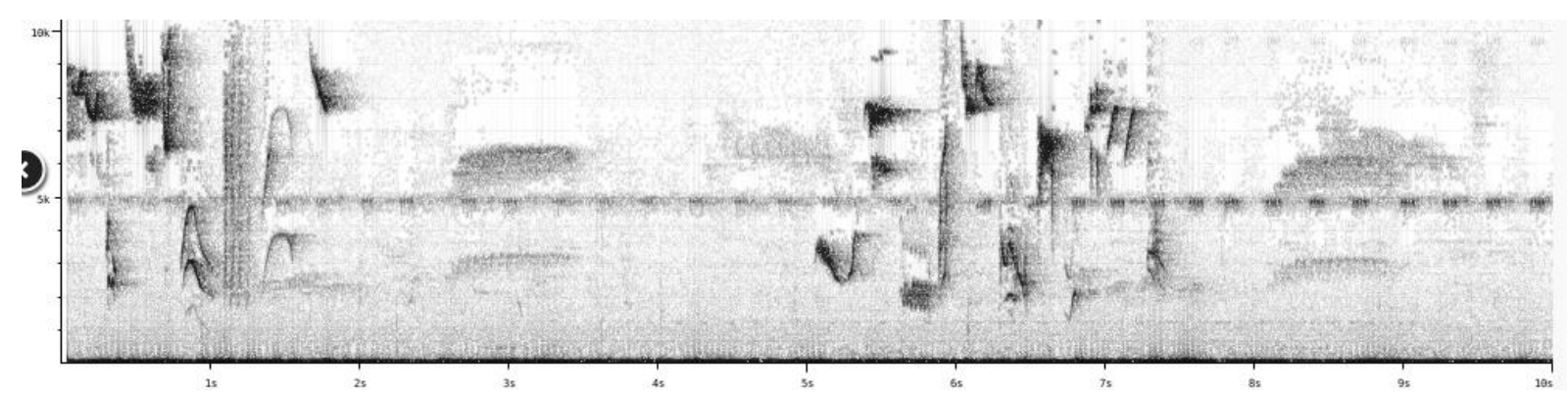

Call
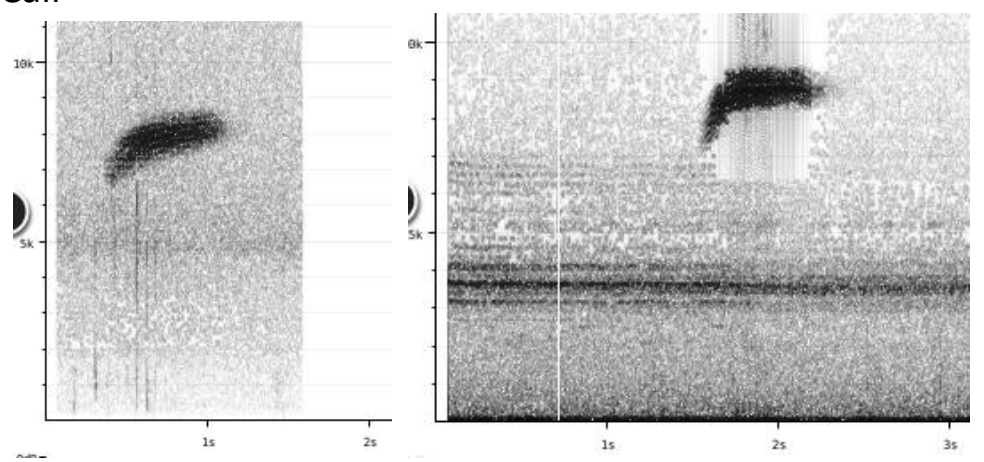

Voice of races chubbi and leucogenys apparently quite different:

Song of chubbi starts with a few pure (often flat-pitched) whistles alternated more and more with high-pitched notes (which are barely audible at some distance).

Song of leucogenys consists of mainly high-pitched notes, with short rather subdued notes at lower pitch, giving it a much more squeaky sound quality.

Also call notes are different: chubbi has a descending high-pitched note with two (nonharmonic) frequency bands, leucogenys has a rising high-pitched note with a single frequency band.

These differences could be scored as follows: leucogenys has a rising call (quantified by end freq. - start freq., score 2-3); song structure different and mainly in high-frequency range (quantified by peak power frequency., score 1-2). Total score about 4.

The situation of gularis is less clear due to some uncertainty about its song (as there is possible confusion with Yellow-legged Trush Turdus flavipes), but both available examples are different from other races, and description in literature (Hilty 2003) also suggests a song which is quite different from chubbi (rather a continuous medley of different notes, as in the 2nd sonogram depicted above, which would be quite different from the short song phrases of both other races) (allow score 1 for this 'indication of difference').

There is however no doubt that also call is different from the other races: a very high-pitched descending note with a single frequency band (starting at slightly over $10 \mathrm{kHz}$, while base freq. of other races stays well under $10 \mathrm{kHz}$ ) (score $2 \mathrm{vs.} \mathrm{other} \mathrm{races).}$

Total vocal score of gularis vs. other races is thus about 3 (with more recordings needed to fully assess vocal difference of song).

This note was finalized on 19th April 2016, using sound recordings available on-line at that moment. We would like to thank in particular the sound recordists who placed their recordings for this species on XC and ML: Roger AhIman, Ciro Albano, Marcus Braun, Paul Coopmans, Eliana Fierro-Calderón, Rodney Fuentes, Steve Hilty, Jose Jacomelli, Olaf Jahn, Joe 
Klaiber, Niels Krabbe, Dan Lane, Oscar Laverde, Jonas Nilsson, Brian O'Shea, Ted Parker, Robert Ridgely, Mark Robbins, Andrew Spencer and Sebastian Vizcarra.

\section{References}

Hilty, S.L. (2003). Birds of Venezuela. Helm Gield Guides. Christopher Helm. London.

Tobias, J.A., Seddon, N., Spottiswoode, C.N., Pilgrim, J.D., Fishpool, L.D.C. \& Collar, N.J. (2010). Quantitative criteria for species delimitation. Ibis 152(4): 724-746.

\section{Recommended citation}

Boesman, P. (2016). Notes on the vocalizations of Rufous-brown Solitaire (Cichlopsis leucogenys). HBW Alive Ornithological Note 301. In: Handbook of the Birds of the World Alive. Lynx Edicions, Barcelona. (retrieved from http://www.hbw.com/node/1251755 on 14 October 2016). 